\title{
GÊNEROS DE RESUMO EM EVENTOS ACADÊMICOS: INTER-RELAÇÕES TEXTUAIS E CONTEXTUAIS
}

\author{
ABSTRACT GENRES IN ACADEMIC CONFERENCES: \\ TEXTUAL AND CONTEXTUAL INTER-RELATIONSHIPS
}

\author{
John Hélio Porangaba de Oliveira* \\ Benedito Gomes Bezerra**
}

\begin{abstract}
RESUMO
Os espaços contextuais de eventos acadêmicos constituem um sistema de atividades organizado de forma hierárquica, em que os gêneros de resumo, objeto deste estudo, surgem numa variação especificada em resumo de comunicação e resumo de trabalho completo, constituindo relações de contexto e de agrupamentos. Neste trabalho, nosso objetivo é analisar como esses gêneros de resumo são organizados, produzidos e identificados, considerando o contexto e as consequentes variações textuais que incidem sobre a noção prototípica do gênero resumo. O estudo, baseado na teoria de gêneros de Swales (1990) e Bhatia (2004; 2009) e na concepção de contexto defendida por van Dijk (2012), compreende a análise contextual e textual de ambas as modalidades de resumo. Os resultados sugerem que o contexto indica as ações sociais necessárias para a realização dos objetivos comunicativos dos participantes, por meio de gêneros inter-relacionados e agrupados em colônias de gêneros. Além disso, essa ação do contexto se reflete na configuração retórica do texto nas diferentes modalidades de resumo.

Palavras-chave: gêneros acadêmicos; resumo de comunicação; resumo de trabalho completo.
\end{abstract}

\section{ABSTRACT}

The contextual spaces of academic events constitute a system of activities organized in a hierarchical way, in which the abstract genres, object of this study, appear in a variation specified in conference abstracts and complete work abstracts, constituting context and group relations. In this work, our aim is to analyze how these abstract genres are organized, produced and identified, considering the context and the consequent textual variations that affect the prototypical notion of the abstract genre. The study, based on the genre theory of Swales $(1990)$ and Bhatia $(2004 ; 2009)$ and on the conception of context defended by van Dijk (2012), comprises the contextual and textual analysis of both modalities of abstracts. The results suggest that context indicates the social actions necessary for the achievement of the participants' communicative objectives, through genres interrelated and grouped into genre colonies. In addition, this contextual action is reflected in the rhetorical configuration of the text in the different classes of abstracts.

Keywords: academic genres; conference abstract; complete work abstract.

\section{INTRODUÇÃO}

O crescente desenvolvimento científico tem levado pesquisadores a participar e a interagir cada vez mais em contextos de eventos acadêmicos. A produção de textos em diferentes gêneros nesses espaços torna possível o progresso científico e contribui para o reconhecimento das práticas de vida da comunidade acadêmica, enfatizando as materialidades escritas que tipificam os papéis de estudantes e professores como pesquisadores. Essa produção é regida por normas, valores e ideologias que tanto constituem como são constituídas por uma linguagem específica do domínio científico.

Analisar gêneros, nesse contexto, é importante para que se tenha uma noção mais ampla sobre atividades de linguagem na relação entre gênero e contexto e na relação entre diferenças e variações de gêneros implicadas pelas necessidades e convenções de interação social e ações comunicativas requeridas no ambiente acadêmico. A propósito dessa questão, entendemos que as práticas sociais e culturais são dependentes da compreensão de contextos gerais e específicos envolvida no reconhecimento de ações letradas (STREET, 2014; BAZERMAN, 2015; MCGRATH; KAUFHOLD, 2016).

Entre tais ações letradas, o gênero resumo acadêmico tem sido uma prática largamente investigada por pesquisadores nos estudos da linguagem, revelando uma variedade de configurações genéricas nomeadas como resumo: resumos de artigo científico (BHATIA, 1993), resumos de dissertação de mestrado (BIASI-RODRIGUES,

\footnotetext{
* Doutorando na Universidade Católica de Pernambuco (UNICAP), Recife, PE, Brasil. jhpoingles@gmail.com

Orcid: https://orcid.org/0000-0002-5478-9081

** Universidade Católica de Pernambuco (UNICAP), Universidade de Pernambuco (UPE), Recife, PE, Brasil. beneditobezerra@gmail.com Orcid: https://orcid.org/0000-0002-7382-0937
} 
1998; ZAKIR; FUNO; 2011), resumo acadêmico de atividades de sala de aula (BORBA, 2004), resumo de tese (CARVALHO, 2010), resumo de dissertação e tese (MEDEIROS, 2015), resumo de comunicação (MIRANDA, 2014; OLIVEIRA, 2017) e resumo de trabalho completo em anais de eventos (OLIVEIRA, 2020), dentre outros.

Ao nos concentrarmos especificamente no contexto de eventos acadêmicos, verificamos que essa variedade do que chamaremos de "gêneros de resumo" ou simplesmente "gêneros resumo" se manifesta na forma de duas modalidades de resumo intimamente relacionadas. Trata-se da produção do "mesmo" gênero obedecendo a uma variação de função, de momento de produção e de propósitos comunicativos, mantendo, contudo, uma autoria única. Nomeamos esses gêneros como resumo de comunicação para eventos e resumo de trabalho completo para anais.

Essas modalidades do gênero resumo demandam uma compreensão comparativa e contrastiva sobre como elas se organizam em uma dinâmica de produção contextual e textual, aspecto ainda não contemplado nas pesquisas a que tivemos acesso. A questão que levantamos diz respeito aos aspectos determinantes da variação entre o resumo de comunicação em eventos e o resumo de trabalho completo para anais, considerando que são escritos no mesmo contexto de interação acadêmica (o evento científico) e que são produzidos pelo mesmo autor, em dois momentos temporal e retoricamente distintos. Apesar da presumível relação desses gêneros com o resumo de artigos científicos, especialmente da parte do resumo de trabalho completo, nossa tese é de que as citadas modalidades de resumo, incluindo o próprio resumo de artigos, constituem diferentes unidades-membros de uma mesma colônia de gêneros (BHATIA, 2009).

O objetivo deste trabalho é, portanto, analisar como os gêneros resumo de comunicação em eventos e resumo de trabalhos completos em anais de eventos são organizados, produzidos e identificados, considerando o contexto, a ideia prototípica de resumo e suas variações textuais e de sentido como um complexo de ações letradas.

Em virtude de seu objetivo, o trabalho está organizado em três tópicos além desta introdução e das considerações finais. No primeiro, incluímos uma abordagem dos conceitos de contexto, colônia de gêneros e cadeia de gêneros como enquadres para a compreensão do processo de produção e da constituição retórica dos referidos gêneros. No segundo tópico, apresentamos os princípios e procedimentos metodológicos que orientaram a análise. No terceiro tópico, apresentamos as análises contextual e textual das modalidades de resumo em foco e discutimos seus resultados.

\section{CONCEITOS TEÓRICOS PARA ANÁLISE DE GÊNEROS}

Neste tópico, situamos o estudo em relação aos conceitos de linguagem, letramentos acadêmicos, gênero, cadeia e colônia de gêneros, resumo e contexto, como um requisito para a análise de como os gêneros resumo de comunicação e resumo de trabalho completo são organizados, produzidos e identificados em eventos acadêmicos. A definição desses conceitos possibilita um olhar mais amplo, integral e aprofundado para a análise de gêneros acadêmicos.

Em um sentido mais amplo, situamos o estudo dos gêneros em um conceito de linguagem como sistema adaptativo complexo, conforme discutido por Larsen-Freeman (1997), Cameron e Larsen-Freeman (2008) e Paiva (2019), entre outros. Essa concepção possibilita a compreensão dos gêneros em uma relação dinâmica e complexa em que mudanças e adaptações surgem motivadas pelos modos de construção de contextos, influenciando, nesse caso, a produção de gêneros dentro de seu respectivo sistema de atividades.

A compreensão da linguagem como sistema adaptativo complexo nos leva à concepção de letramentos acadêmicos (STREET, 2010; LEA; STREET, 2006; BEZERRA, 2012; MCGRATH; KAUFHOLD, 2016; VIANNA et al., 2016; BEZERRA; LÊDO, 2018), que enquadra um conjunto de outras concepções envolvendo leitura e escrita, mas também fala e escuta, situados em práticas e eventos de letramento. Portanto, compreendemos letramentos acadêmicos como formas de ação e participação social no processo de desenvolvimento e produção do conhecimento. As práticas de letramento subjacentes a esse processo fundamentam formas de agir, de ser, de compreender e de produzir atividades de linguagem na relação com modelos contextuais e cognitivos das ações sociais.

A referida interpretação sobre letramentos acadêmicos enfatiza ações contextualizadas como eventos de letramentos em práticas letradas realizadas através de gêneros como modos de vida, formas de ser e agir em uma profissão nos processos das atividades socialmente organizadas (BAZERMAN, 2011; BEZERRA; LÊDO, 2018). De acordo com Bezerra e Lêdo (2018, p. 202), "os letramentos acadêmicos se constituirão, por assim dizer, como 
sinônimos de letramentos em gêneros próprios do ambiente universitário", em que se dá lugar para inter-relações contextuais e textuais.

A propósito disso, Motta-Roth (2011, p. 165) sugere que a relação ente texto e contexto permite compreender o "gênero como um fenômeno social e linguístico, como um sistema de eventos comunicativos culturalmente situados, como linguagem". Inferimos, portanto, a existência de uma complexa relação entre gênero e contexto para compreender atividades de linguagem específicas situadas em atividades de linguagem gerais e globais.

Os gêneros, especificamente, são concebidos neste trabalho como uma "classe de eventos comunicativos cujos membros compartilham um conjunto de propósitos comunicativos", seguindo a perspectiva de Swales (1990, p. 58). Bhatia detalha essa definição ao afirmar que o gênero é "um evento comunicativo reconhecível, caracterizado por um conjunto de propósitos identificados e mutuamente entendidos pelos membros da comunidade profissional ou acadêmica na qual ele regularmente ocorre" (1993, p. 13). Embora não o tomemos como um dado a priori e sim como um resultado da análise de gêneros, entendemos o propósito comunicativo como um aspecto fundamental para a identidade e a identificação do gênero. Na dimensão textual, os propósitos comunicativos do gênero são realizados por meio de unidades retóricas denominadas moves ou movimentos, os quais, de acordo com Swales (2004, p. 228), se caracterizam por realizar "dentro do discurso escrito ou falado, uma função comunicativa coerente".

Definidas as concepções de linguagem, letramentos acadêmicos e gêneros, outro conceito teórico relevante para este estudo é o conceito de cadeia de gêneros, conforme empregado por Räisänen (1999) e Swales (2004) e, no contexto brasileiro, por Nobre e Biasi-Rodrigues (2012) e por Bezerra (2017). A principal característica de uma cadeia de gêneros é o ordenamento cronológico dos gêneros envolvidos em uma dada interação comunicativa. No caso de um evento acadêmico, o conceito de cadeia de gêneros permite visualizar sequencialmente tanto os gêneros "oficiais", visíveis para todos os participantes, como os gêneros "oclusos" ou de suporte, invisíveis para outsiders ou membros iniciantes da comunidade acadêmica (SWALES, 2004, p. 18). Trata-se, por conseguinte, de um conceito potencialmente produtivo para a pesquisa e análise de gêneros inter-relacionados, do ponto de vista de sua produção e circulação. Uma cadeia de gêneros expressa processos hierarquicamente constituídos, em que cada ação social por meio de um gênero somente acontece após ser desencadeada por outra no desenvolvimento de uma prática comunicativa.

O conceito de colônia de gêneros, por sua vez, foi proposto por Bhatia $(2004,2009)$ e aplicado por Bezerra $(2006 ; 2007 ; 2017)$ ao estudo de gêneros introdutórios em livros acadêmicos, por Pimentel (2014) ao estudo de gêneros emergentes no aplicativo de redes sociais Facebook e por Oliveira (2017) ao estudo de resumos de comunicação, entre outros. Refere-se a um agrupamento de gêneros intimamente relacionados por propósitos comunicativos semelhantes, mas que se distinguem por aspectos outros como os participantes, os processos e a situação de produção envolvidos.

A noção de colônia de gêneros possibilita, neste estudo, situar o resumo de comunicação e o resumo de trabalho completo como integrantes de um mesmo agrupamento de gêneros, relacionados não mais por sucessão cronológica apenas, como analisado por meio da cadeia de gêneros, mas por critérios mais discursivos e contextuais, determinados pelos propósitos comunicativos e por outros fatores que condicionam sua produção. Conforme Bhatia (2009), os gêneros, bem como seus propósitos comunicativos, podem ser analisados de modo mais genérico ou de modo mais específico. No primeiro caso, falaríamos apenas de resumo. No segundo caso, torna-se possível distinguir as duas modalidades por meio de um olhar mais acurado para as especificidades de seus propósitos. A propósito, afirmar que o resumo não constitui um gênero singular e sim uma colônia de gêneros é o que justifica utilizarmos a expressão "gêneros resumo" ou "gêneros de resumo".

Ao delinear uma colônia de gêneros de resumo, Oliveira (2017) conclui que os membros dessa colônia manifestam um propósito comunicativo comum ligado a uma "função resumitiva", recorrente em todas as modalidades de resumo, e que os propósitos comunicativos específicos de cada gênero resumo se referem a ações comunicativas contextuais, por um lado, e à ação de resumir vinculada ao documento específico a que a produção do resumo atende.

Uma vez que se configura como uma colônia de gêneros e não como um gênero singular, a terminologia a respeito de resumo pode variar de acordo com a proposta e o entendimento de cada pesquisador. Em decorrência do conceito de colônia de gêneros, entendemos, com Oliveira (2017, p. 44), que "o resumo é um termo polissêmico para muitos gêneros resumo". Especificamente, para os fins deste trabalho, a expressão resumo de comunicação é tomada como designação de uma produção textual desenvolvida para submissão a uma comissão científica, com vistas à participação em um evento acadêmico nas modalidades de comunicação oral ou sessão de pôsteres. A ação 
de resumir requerida pelo resumo de comunicação atende, assim, a um propósito comunicativo estabelecido pela comunidade acadêmica, o de servir como requisito para o acesso ao espaço de divulgação da pesquisa científica no contexto dos eventos acadêmicos (MIRANDA, 2014; OLIVEIRA, 2017). Neste trabalho, o modelo de organização retórica utilizado como ponto de partida para a análise do resumo de comunicação foi desenvolvido por Oliveira (2017)

Quanto ao resumo de trabalho completo em anais de eventos ${ }^{1}$, com esse termo nos referimos ao resumo que acompanha o trabalho completo submetido para publicação nos anais de um evento científico do qual o autor participou previamente e ao qual primeiramente submeteu o resumo de comunicação, seguido da efetiva comunicação oral ou apresentação de pôster acadêmico. Não encontramos referência a essa terminologia na literatura sobre gêneros, mas nos aproximamos de sua compreensão a partir de Bhatia (1993), ao se referir ao resumo de artigo de pesquisa como um gênero em que se descreve o que o autor fez, como o autor fez, o que o autor descobriu e o que o autor concluiu e, portanto, como uma produção última, que surge como parte constitutiva do trabalho completo, o artigo de pesquisa. Assim, neste estudo, utilizamos um modelo descritivo inspirado em Bhatia (1993) para o resumo de artigo científico como base para a análise do resumo de trabalho completo submetido a anais de eventos científicos.

Por fim, o conceito de contexto adotado neste estudo ancora-se nos postulados de van Dijk (2012, p. 157 158), para quem "os contextos não são algum tipo de situação social ou comunicativa, mas sim construções subjetivas ou 'definições' das dimensões relevantes de tais situações por parte dos participantes", operando por meio de modelos mentais. Assim, entendemos contexto como um fenômeno de compreensão do modo de agir linguística e retoricamente como resposta, na produção de gêneros escritos, a eventos acadêmicos como um modelo de contexto.

Essa linha de compreensão do conceito de contexto nos permite inferências sobre a produção dos gêneros, em uma cadeia de gêneros, como um requisito de adequação de ações e propósitos comunicativos. Em outras palavras, a produção de um dado gênero surge em resposta ou na relação com gêneros antecedentes (DEVITT, 2004; BEZERRA, 2017), o que demanda o compartilhamento de modelos mentais por parte dos produtores sobre o que a situação exige, para que a produção do gênero requerido naquele momento seja adequada, organizada e adaptada à coerência situacional e comunicativa, em linha com os gêneros antecedentes.

Para fundamentar essa posição interpretativa, no próximo tópico descrevemos as ações metodológicas que nos permitem enquadrar as concepções aqui expostas na significação de que a produção de resumos caracteriza ações letradas organizadas para a realização dos objetivos comunicativos dos membros da comunidade acadêmica.

\section{PROCEDIMENTOS METODOLÓGICOS}

Os textos que compõem o corpus deste estudo foram produzidos por estudantes de pós-graduação e professores no exercício de sua identidade de pesquisadores, apresentando e publicando trabalhos em eventos científicos e seus anais. Assim, analisamos um conjunto de 15 resumos de comunicação e 14 resumos de trabalho completo, totalizando 29 textos. Os textos foram coletados nos anais online do evento acadêmico IX Simpósio Internacional de Estudos de Gêneros Textuais (IX SIGET), realizado no ano de 2017. A coleta aconteceu em dois momentos temporalmente distintos: no primeiro, foram coletados os 15 resumos de comunicação. Em um segundo momento, procedeu-se a coleta dos 15 trabalhos completos correspondentes às comunicações, no corpo dos quais se encontra o respectivo resumo. Contudo, posteriormente constatamos que um dos trabalhos publicados não continha o resumo. Preferimos manter a discrepância até por ela ilustrar certa flexibilidade nos procedimentos para publicação em anais de eventos.

No tratamento dos dados, além de uma análise contextual mais ampla, cada texto do corpus foi submetido a uma investigação tanto em termos de organização retórica como em termos de ações linguísticas, aliadas aos aspectos contextuais mobilizados na escrita.

Para a análise contextual, levamos em conta a perspectiva analítica multidimensional sugerida por Bhatia (2004), abrangendo os procedimentos de análise textual, por um lado, e os aspectos sociocognitivos, etnográficos e sociocríticos, por outro lado, para dar conta do contexto. Esses aspectos, entrelaçados, contemplam elementos

1. O resumo de trabalho completo não equivale, do ponto de vista retórico e dos propósitos comunicativos, ao resumo de artigo científico porque, embora se trate de produções certamente similares, talvez até idênticas do ponto de vista textual, o "trabalho completo" e o artigo científico diferem quanto ao contexto, aos produtores e ao crivo científico que determinam sua publicação. 
"textográficos" ${ }^{2}$, modos de vida, práticas de escrita e de leitura e comportamento interpretativo. Nesse sentido, a noção de cadeia de gêneros como agrupamento hierárquico e sequencial de gêneros inter-relacionados propicia o estudo dos gêneros em conexão com as práticas sociais, que também condicionam a inter-relação dos gêneros em termos de colônia de gêneros.

Para a análise textual, a metodologia adotada neste trabalho segue os parâmetros da análise de movimentos retóricos (move analysis) baseada no trabalho original de Swales (1990), consistindo em descrever a estrutura retórica ou a "distribuição das informações" (como propõe Biasi-Rodrigues (1998) em seu estudo de resumos de dissertação de mestrado) em exemplares textuais do gênero em foco. Consideramos as estruturas retóricas e os respectivos elementos linguísticos como estratégias que os produtores dos resumos desenvolvem na materialidade textual segundo as convenções genéricas estabelecidas, embora sempre haja margem para inovação e para exploração das referidas convenções (TARDY, 2016). Para a operacionalização da análise, aplicamos um modelo descritivo de movimentos e passos retóricos aos gêneros resumo de comunicação e resumo de trabalho completo com base nos trabalhos de Oliveira (2017) e Bhatia (1993), respectivamente. Como informado anteriormente, o modelo de Oliveira (2017) surgiu de estudo dos próprios resumos de comunicação, enquanto o modelo descritivo de Bhatia (1993) se refere originalmente a resumos de artigo científico.

\section{OS GÊNEROS RESUMO NA RELAÇÃO ENTRE CONTEXTO E TEXTO}

Neste tópico, apresentamos, pela ordem, as análises contextual e textual do corpus e, em seguida, procuramos discutir os resultados a que chegamos.

\section{Análise dos aspectos contextuais}

Verificamos que o contexto dos eventos acadêmicos está inserido em um contexto mais amplo de área disciplinar, além de um contexto institucional e, de forma talvez mais difusa, também está enquadrado no contexto de uma comunidade discursiva acadêmica. Cada contexto realiza um modo específico de percepção e apreensão de conhecimentos diversos que de algum modo influenciam a produção de gêneros específicos, exigindo formas particulares de interpretar e de produzir textos em diferentes gêneros. Os contextos, dessa forma, condicionam e restringem os gêneros, uma vez que a cada enquadre contextual corresponde uma maneira variada de realizar o resumo.

Os contextos dos eventos acadêmicos são subsumidos ainda por uma noção ampla de letramentos acadêmicos realizados por meio de gêneros típicos da comunidade discursiva de referência, configurando espaços modelares da percepção social, retórica e cognitiva. E é essa percepção, em um espectro micro e macrocontextual, que organiza os textos em gêneros da linguagem como sistema adaptativo complexo, em constante mudança receptiva e interpretativa na realização de seus propósitos comunicativos.

A seguir organizamos um conjunto de figuras que procuram sintetizar os resultados desta análise. A Figura 1 representa um olhar para o contexto que segue do específico para o geral, qual seja, dos contextos menores do evento científico e da área disciplinar até os contextos mais amplos, institucional e acadêmico (comunidade discursiva acadêmica).

2. Em Swales (1998), o estudo etnográfico de culturas disciplinares em um pequeno prédio da Universidade de Michigan é descrito como "textografia" por se basear em textos para entender as referidas culturas. 


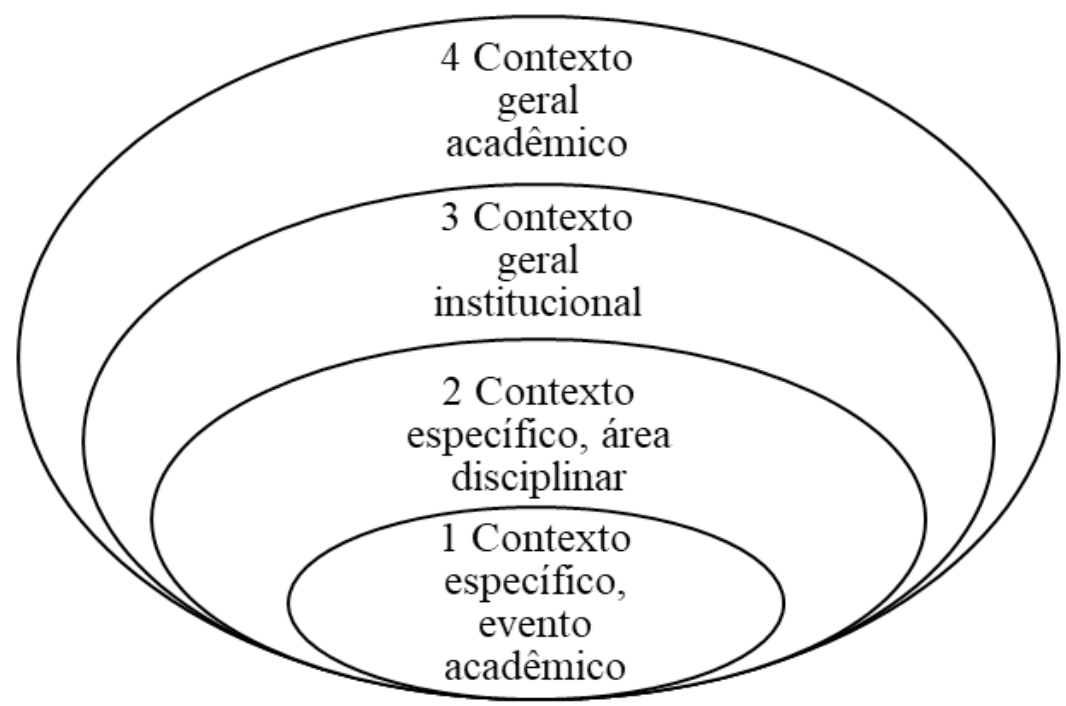

Figura 1. Níveis de contexto

Fonte: Elaboração própria

Essa representação gráfica dos contextos sinaliza uma aproximação de caráter etnográfico, mais especificamente, a partir de elementos textográficos, como acesso a modos de vida e práticas de escrita, relacionada com uma concepção sociocognitiva de leitura e comportamento interpretativo. Essa representação etnográfica/textográfica busca sintetizar toda a dimensão sociocognitiva em que estudantes de pós-graduação e professores, enquanto pesquisadores, estão envolvidos, conforme ilustrado também nas figuras 2 e 3.

A Figura 2 representa práticas de letramento vinculadas a eventos acadêmicos, com seus respectivos eventos de letramento, situados por uma orientação comunicativa. A imagem, de forma específica, está centrada no modelo de contexto da situação comunicativa dentro do evento acadêmico a que foram submetidos os resumos tratados neste trabalho, ou seja, o resumo de comunicação como proposta de comunicação oral ou de apresentação de pôsteres e o resumo de trabalho completo, juntamente com este, como relato mais amplo da pesquisa apresentada oralmente, destinado à publicação nos anais do evento.

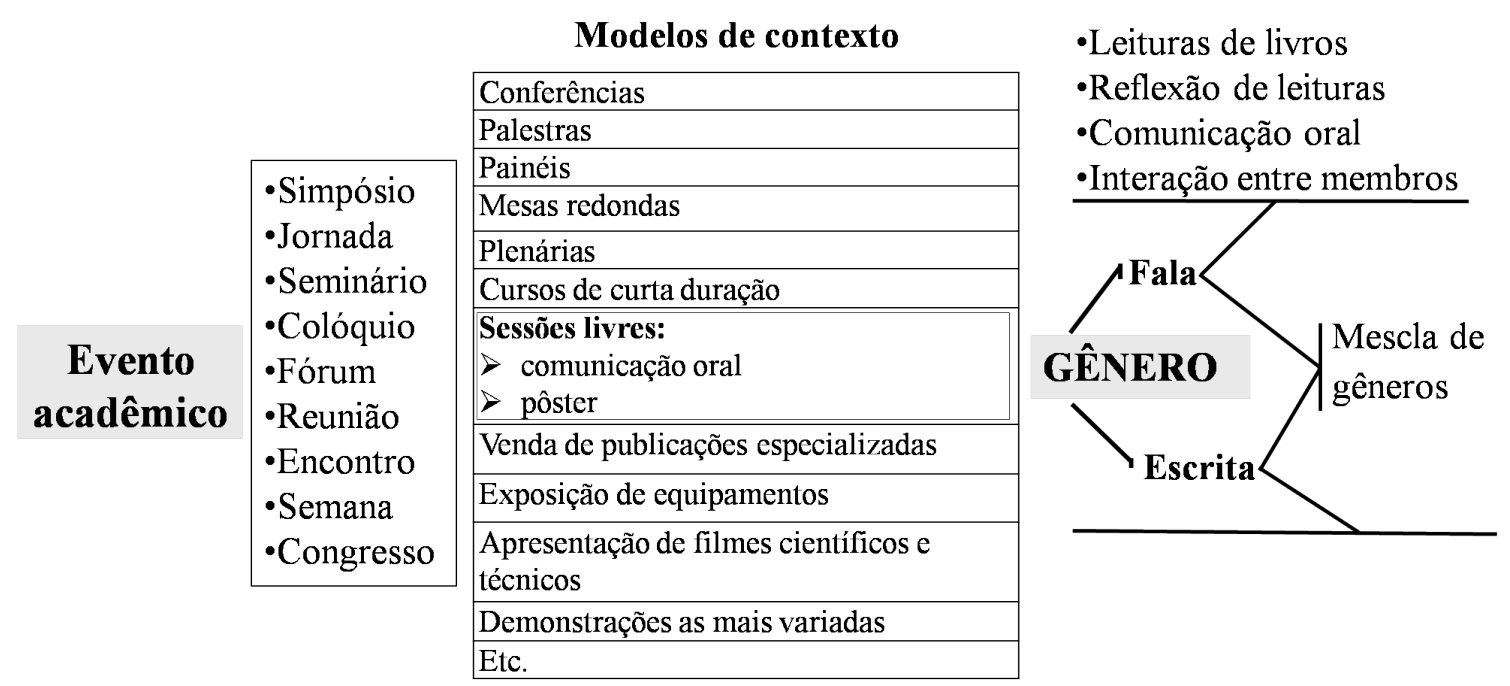

Figura 2. Modelo de contexto: sessões de comunicação oral e sessões de pôsteres Fonte: Elaboração própria

Como já mencionado, nessa representação, temos a possibilidade de visualizar o modelo de contexto constituído pelo evento acadêmico IX SIGET. A seguir, na Figura 3, inserimos diferentes contextos e percepções mais específicas, por um lado, e mais gerais, por outro, do que seja um evento acadêmico situado em suas diferentes dimensões contextuais. A referência da análise contextual desenvolvida a partir das imagens, proposta sempre na 
ótica de um movimento do específico para o geral, pretende oferecer uma visão holística da realidade da produção dos gêneros de resumo, nosso objeto de estudo, a partir do exemplo do evento acadêmico IX SIGET.

A dimensão mapeada de um macrocontexto na Figura 3, a seguir, nos possibilita uma descrição hierárquica do sistema de atividades, fundamentada no conceito de cadeia de gêneros (cf. Figura 4). O mapeamento macrocontextual da Figura 3 foi desenvolvido a partir da concepção de letramentos sociais de Street (2014), fazendo referência a práticas comunicativas numa perspectiva etnográfica/textográfica, de práticas e eventos de letramentos.

Além disso, incluímos, com base no formulário e na terminologia da Plataforma Lattes do CNPq, um mapeamento dos gêneros de prestígio acadêmico que são previstos para registro no Currículo Lattes (no caso aqui descrito, as informações foram verificadas no currículo de três membros experientes da comunidade acadêmica).

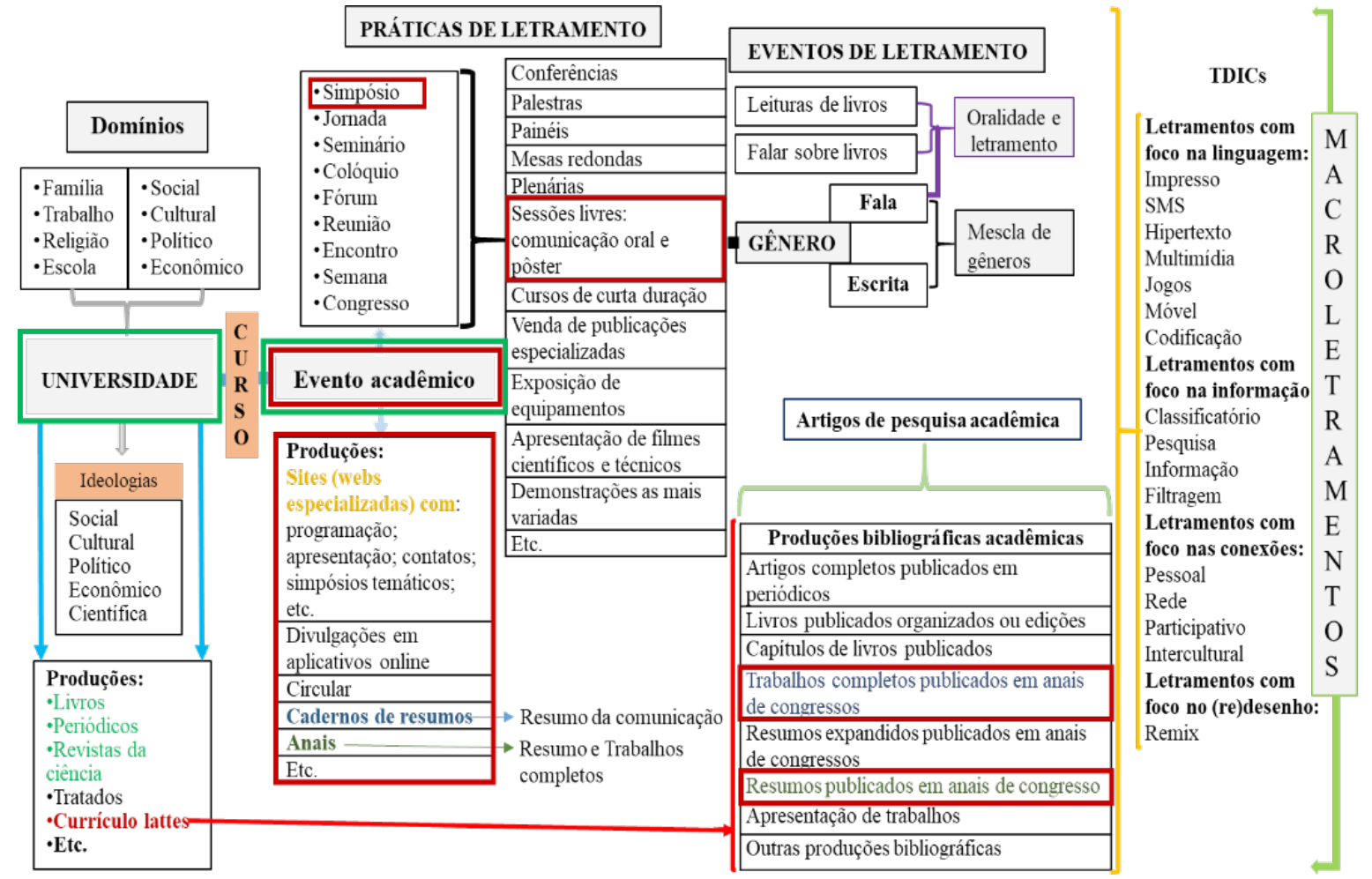

Figura 3. Relações contextuais enquanto forma de letramento

Fonte: Elaboração própria

Nesta etapa da análise, verificamos a variação de dois gêneros que são virtualmente idênticos, do ponto de vista da materialidade textual, mas que apresentam terminologias distintas em relação ao contexto de publicação e circulação (diferentes formas de socialização acadêmica). Na Plataforma Lattes, esses gêneros são nomeados como "artigos completos publicados em periódicos" e "trabalhos completos publicados em anais de congressos". Por essa terminologia, compreende-se que o "trabalho completo" também se configura, do ponto de vista textual e estrutural, como um artigo, assim como o artigo é uma forma de "trabalho completo", porém o que os distingue materialmente é o suporte em que são publicados: anais de eventos ("trabalhos"), por um lado, e periódicos (artigos), por outro.

A partir dessa constatação, foi possível conjecturar que o modelo descritivo do gênero "resumo de artigo de pesquisa", apresentado por Bhatia (1993), poderia ser aplicado à descrição do resumo de trabalho completo que estamos empreendendo neste estudo. Ainda é possível constatar que a Plataforma Lattes também reserva espaço para o registro de "resumos publicados em anais de congresso", o equivalente ao gênero a que nos referimos como resumo de comunicação.

Considerando que a descrição pormenorizada da Figura 3 fugiria ao escopo deste trabalho, ressaltamos o papel desse mapeamento em explicitar as dimensões dos modelos contextuais e cognitivos com que lidam os pesquisadores, sejam eles estudantes ou professores. Conquanto provavelmente se trate, na maioria dos casos, de um modelo cognitivo implícito, talvez pelo menos parcialmente inconsciente, o quadro expressa práticas de vida e ações letradas inter-relacionadas, articuladas a conhecimentos diversos e indissociáveis da realidade dos pesquisadores 
como membros de uma comunidade acadêmica e produtores de gêneros diversos, inclusive de variedades de resumos, em contextos muito específicos.

Assim, a Figura 3 evidencia a importância de uma noção de contexto como modelos (cognitivos) de contexto e tipos de situação que orientam a produção escrita. Entretanto, a Figura 3 nos leva a uma visão global das interações acadêmicas em que se insere a produção dos resumos analisados neste estudo. Por isso, mais uma vez nos voltamos para o contexto específico, delineando a cadeia de gêneros conforme ocorreu no evento acadêmico IX SIGET. Através do mapeamento da cadeia de gêneros do evento, fica manifesta a distribuição não só dos gêneros mais visíveis no campo de nossa compreensão, mas também daqueles gêneros de que normalmente não nos damos conta quando refletimos sobre a produção científica.

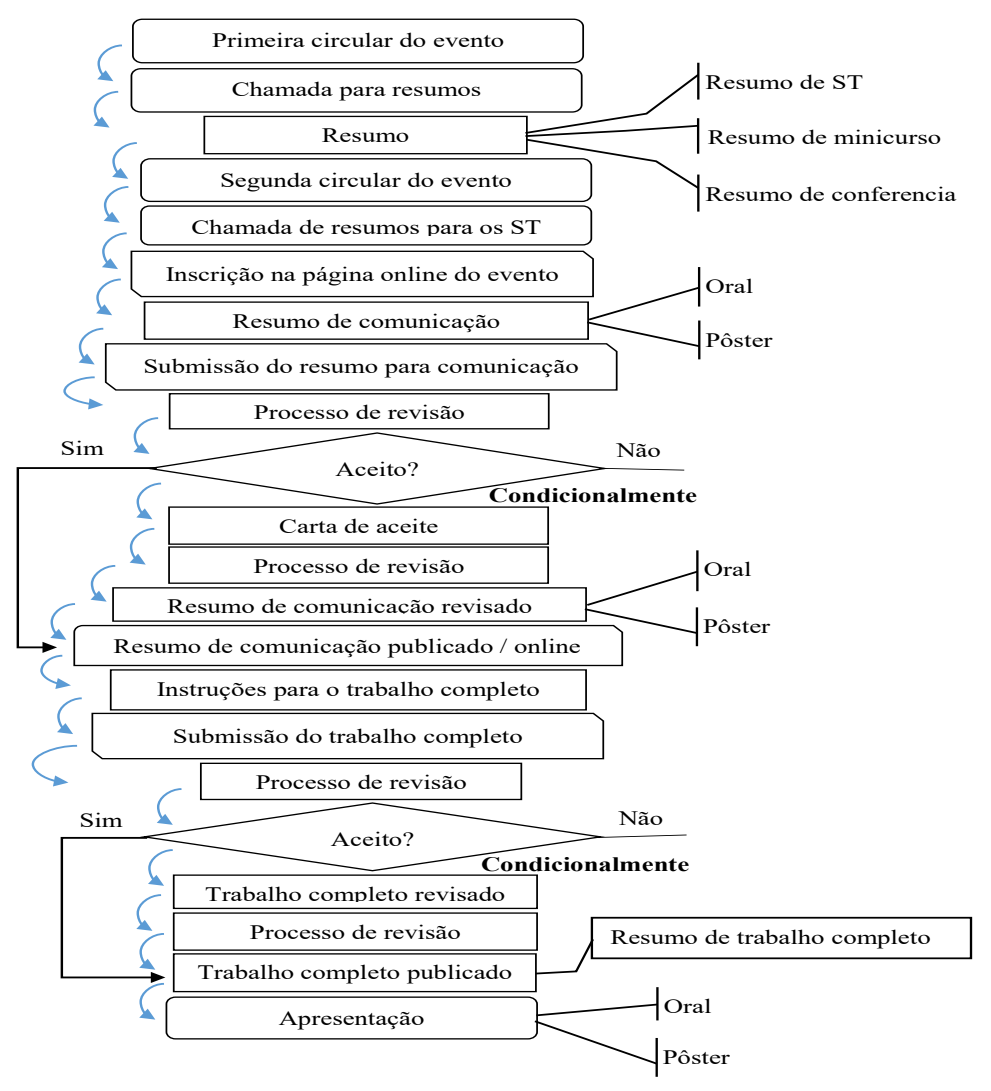

Figura 4. Cadeia de gêneros do evento IX SIGET

Fonte: Elaboração própria

A análise de gêneros apoiada no procedimento analítico contextual representado pelas figuras 1 , 2 e 3 forneceu o devido embasamento para a aplicação do conceito de cadeia de gêneros ao evento acadêmico IX SIGET. A Figura 4 explicita a percepção de como os gêneros se inter-relacionam e de como um gênero condiciona a produção de outro gênero, posto como o próximo elo na cadeia. Por outro lado, gêneros como o resumo de comunicação e o resumo de trabalho completo não só requerem a realização do próximo elo da cadeia, mas nela aparecem como uptakes ou "apreensões" (FREADMAN, 2002) de gêneros antecedentes.

No fluxo de produção da cadeia de gêneros, a iniciativa parte da comissão organizadora do evento acadêmico, a quem cabe realizar uma chamada de trabalhos na forma de uma circular dirigida aos pesquisadores. Esse gênero funcionará como antecedente para a produção e submissão de resumos como propostas de simpósios temáticos. Posteriormente, nova circular realizará chamada de trabalhos para a submissão de resumos para comunicação oral nos simpósios temáticos aprovados. Bem mais adiante na cadeia, o resumo de trabalho completo integrará o texto escrito como registro da pesquisa apresentada em comunicação oral, atendendo a uma nova chamada ou a uma data fixada em chamadas anteriores, desta vez para publicação do trabalho completo nos anais do evento acadêmico. Em síntese, a partir da produção, submissão e aprovação do resumo de comunicação, seguida de sua apresentação oral durante o 
evento, surge o resumo de trabalho completo, agora entendido como parte necessária do próprio trabalho completo submetido e posteriormente publicado nos anais.

Em nossa observação textográfica, verificamos, nas diretrizes informativas para a produção e submissão dos textos, que os resumos de simpósios temáticos foram produzidos, cada um, por dois ou três pesquisadores doutores de diferentes instituições. Ainda nessa perspectiva, os resumos de comunicação foram submetidos na perspectiva de apresentação em duas possíveis modalidades: comunicação oral, aberta a mestrandos, mestres, doutorandos, doutores e pesquisadores em geral, e sessão de pôsteres, aberta a alunos de graduação, mestrandos e mestres. Os resumos poderiam, quanto a sua extensão, variar entre 100 e 300 palavras, sendo ainda indicado que deveriam obrigatoriamente conter tema, objetivos, quadro teórico-metodológico, resultados (parciais ou finais) e conclusões.

Os trabalhos completos, junto aos quais coletamos a segunda parte dos resumos analisados, foram publicados após a realização do evento acadêmico. As diretrizes estabelecidas para produção do resumo de trabalho completo informavam que o texto do resumo, todo em itálico na primeira página do trabalho completo, deveria ter no máximo 150 palavras. Diferentemente do que foi posto para o resumo de comunicação, as diretrizes do trabalho completo não normatizaram os aspectos que deveriam compor o conteúdo do resumo de trabalho completo. A não ser que o autor seguisse os parâmetros anteriormente postos para o resumo de comunicação, o resumo de trabalho completo foi produzido de forma livre, sem orientação quanto aos elementos informativos a serem incluídos.

Além disso, verificamos que a própria ausência do resumo no corpo do trabalho completo não foi impedimento, pelo menos em um caso verificado em nosso corpus, para sua aprovação e publicação. Coerentemente com nossa concepção de linguagem como sistema adaptativo complexo, entendemos esse caso excepcional como um aspecto da dinâmica e da complexidade das ações comunicativas, tanto no que tange à interpretação das diretrizes pelo autor do trabalho completo como no que diz respeito à aceitação do trabalho sem resumo pela organização do evento. Ressalte-se que as diretrizes, embora não normatizassem o conteúdo do resumo, previa que este deveria constar no corpo do trabalho completo. Portanto, a dinâmica da mudança pode ocorrer de acordo com o modo particular de cada produtor de texto ao interpretar a informação para uma ação e do receptor ao aceitar ou não essa ação.

Ainda em relação ao procedimento analítico do contexto, resta explorar a noção sociocognitiva de gêneros inter-relacionados, que se ajusta à concepção sociocrítica de estudos de práticas sociais, levando ao enquadramento dos gêneros em uma colônia de gêneros, na qual se visualiza uma variedade de gêneros de resumos.

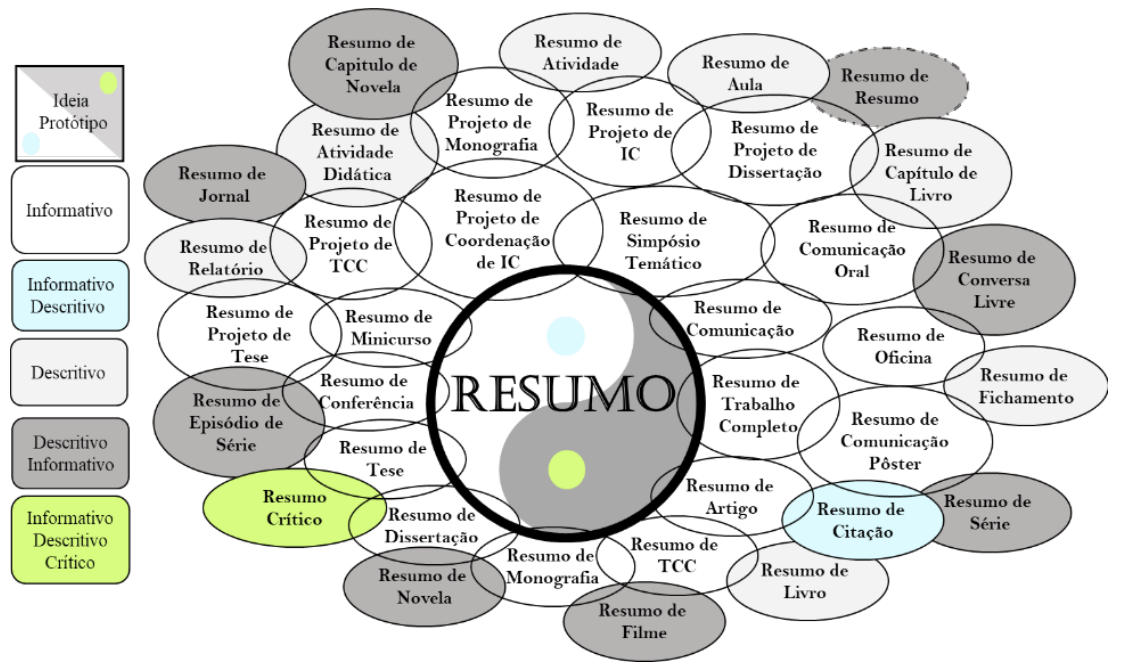

Figura 5. Colônia de gêneros de resumo em uma dimensão macrocontextual Fonte: Elaboração própria

Como afirmamos anteriormente, o resumo é um termo polissêmico para muitos gêneros. Na Figura 5, enumeramos 36 variedades de resumos, todos relacionados em diferentes medidas com um gênero resumo "prototípico", para usar um termo caro a Swales (1990). O resumo de comunicação e o resumo de trabalho completo são, portanto, nessa representação conceitual, membros primários de uma colônia de gêneros de resumos de variada natureza e, mais especificamente, de resumos de caráter acadêmico. 
Passaremos, a seguir, a tratar da análise textual dos gêneros de resumo, observando como esses textos se organizam em termos de estratégias retóricas e linguísticas como indicadoras da dinâmica da linguagem, das mudanças e das adaptações que ocorrem no processo de produção de gêneros em contextos específicos.

\section{Análise dos aspectos textuais}

Inicialmente, a análise textual se concentra na descrição dos padrões textuais, indicativos das estratégias retóricas dos autores dos resumos, e na interpretação dessas estratégias no nível linguístico do texto dos resumos de comunicação.

Tabela 1. Estratégias retóricas em resumos de comunicação ${ }^{3}$

\begin{tabular}{|lc|c|c|}
\hline MOVE 1: ESTABELECER O CONTEXTO & RC & Oco. \\
\hline ER1:Contextualizando a pesquisa & $\mathrm{e} / \mathrm{ou}$ & 15 & 12 \\
\hline ER2: Apresentando o objeto de estudo & $\mathrm{e} / \mathrm{ou}$ & 15 & 6 \\
\hline ER3: Apresentando o problema a ser solucionado & $\mathrm{e} / \mathrm{ou}$ & 15 & 1 \\
\hline ER4: Levantando a hipótese & & 15 & 1 \\
\hline MOVE 2: INTRODUZIR O PROPÓSITO & & \\
\hline ER1: Indicando a intenção do autor & 15 & 2 \\
\hline ER2: Apontando os objetivos & 15 & 11 \\
\hline MOVE 3: DESCREVER A METODOLOGIA & & \\
\hline ER1: Apresentando o quadro teórico-metodológico & $\mathrm{e} / \mathrm{ou}$ & 15 & 11 \\
\hline ER2: Descrevendo os fundamentos teóricos & $\mathrm{e} / \mathrm{ou}$ & 15 & 8 \\
\hline ER3: Incluindo informações sobre o corpus & $\mathrm{e} / \mathrm{ou}$ & 15 & 2 \\
\hline ER4: Descrevendo os procedimentos ou métodos & 15 & 1 \\
\hline ER5: Indicando o escopo da pesquisa & & \\
\hline MOVE 4: SINTETIZAR OS RESULTADOS & 15 & 11 \\
\hline ER1: Apresentando os resultados & & \\
\hline MOVE 5: APRESENTAR AS CONCLUSÕES & 15 & 3 \\
\hline ER1: Apresentando as conclusões & & \\
\hline
\end{tabular}

Fonte: Dados da pesquisa conforme modelo de Oliveira (2017)

$\mathrm{Na}$ análise do resumo de comunicação (RC), conforme a Tabela 1, a elevada recorrência, no Move 1, da Estratégia Retórica 1 (ER1), "Contextualizando a pesquisa" (12 vezes), indica que relatar o contexto da pesquisa é uma estratégia retórica valorizada pelos autores dos resumos. Do mesmo modo, é bastante recorrente apontar os objetivos (Move 2-ER2), apresentar o quadro teórico-metodológico (Move 3-ER1) e apresentar os resultados (Move 4-ER1), todas com 11 ocorrências. Quanto às conclusões, constatamos apenas 03 ocorrências, apesar da exigência de sua inclusão nas diretrizes do evento para o conteúdo do RC, como informamos na análise contextual.

Outras estratégias retóricas presentes no RC, nos três primeiros moves, constituem opções adicionais disponíveis para os autores dos resumos. Embora algumas delas pareçam bastante secundárias ou periféricas, a existência de tais estratégias retóricas evidencia certa plasticidade constitutiva do gênero, em que pese a estabilidade das convenções que o definem.

No todo, a análise indica que as principais estratégias retóricas adotadas pelos autores, ao construírem seus resumos, consistem em contextualizar a pesquisa, indicar seus objetivos, apresentar o quadro teórico-metodológico que a orientou ou orientará e apresentar os resultados parciais ou finais. Opcionalmente, poderão ainda descrever fundamentos teóricos ou suprir informações sobre o corpus. Ao produzir um resumo de comunicação, não é comum apresentar conclusões, ainda que exigido pelo evento, pois muitas vezes a pesquisa a que se refere o resumo ainda não foi realizada ou não está completa.

3. Legenda: move $=$ movimento retórico; $\mathrm{ER}=$ estratégia retórica. 
Nesse sentido, o resumo de comunicação pode ser tratado muito mais como uma espécie de gênero de planejamento do trabalho científico do que como um gênero de relato. Em outros termos, o resumo de comunicação nem sempre é o resumo de um texto-fonte, porque pode preceder o texto maior (trabalho completo) em sua produção. Nesse caso, portanto, a comunidade acadêmica reconhece como resumo o núcleo de um texto maior a ser produzido futuramente e não, como é corrente, a redução de um texto-fonte segundo determinados parâmetros.

Quanto à análise textual do resumo de trabalho completo (RTC), a Tabela 2 registra a ocorrência das estratégias retóricas verificadas nos 14 resumos analisados por meio do modelo descritivo apresentado por Bhatia (1993).

Tabela 2. Estratégias retóricas em resumos de trabalhos completos em anais

\begin{tabular}{|c|c|c|c|}
\hline \multicolumn{2}{|l|}{ MOVE 1: INTRODUZIR O PROPÓSITO } & \multirow{2}{*}{$\begin{array}{c}\text { RTC } \\
14\end{array}$} & \multirow{2}{*}{$\frac{\text { Oco. }}{1}$} \\
\hline ER1: Indicando a intenção do autor & $\mathrm{e} / \mathrm{ou}$ & & \\
\hline ER2: Levantando a hipótese & e/ou & 14 & 0 \\
\hline ER3: Apontando os objetivos & $\mathrm{e} / \mathrm{ou}$ & 14 & 11 \\
\hline ER4: Apresentando o problema a ser solucionado & & 14 & 0 \\
\hline \multicolumn{4}{|l|}{ MOVE 2: DESCREVER A METODOLOGIA } \\
\hline ER1: Apresentando o quadro teórico-metodológico adotado & $\mathrm{e} / \mathrm{ou}$ & 14 & 9 \\
\hline ER2: Incluindo informações sobre o corpus & e/ou & 14 & 3 \\
\hline ER3: Descrevendo os procedimentos ou métodos utilizados & $\mathrm{e} / \mathrm{ou}$ & 14 & 1 \\
\hline ER4: Indicando o escopo da pesquisa & & 14 & 2 \\
\hline \multicolumn{4}{|l|}{ MOVE 3: SINTETIZAR OS RESULTADOS } \\
\hline ER1: Apontando observações sobre os dados analisados & e/ou & 14 & 6 \\
\hline ER2: Apresentando os resultados encontrados & e/ou & 14 & 1 \\
\hline $\begin{array}{l}\text { ER3: Sugerindo soluções para o problema (caso tenha sido ap } \\
\text { no primeiro move) }\end{array}$ & nntado & 14 & 0 \\
\hline \multicolumn{4}{|l|}{ MOVE 4: APRESENTAR AS CONCLUSÕES } \\
\hline ER1: Interpretando os resultados & e/ou & 14 & 2 \\
\hline ER2: Apontando inferências sobre os resultados & $\mathrm{e} / \mathrm{ou}$ & 14 & 2 \\
\hline ER3: Indicando implicações acerca dos resultados obtidos & e/ou & 14 & 0 \\
\hline ER4: Apontando aplicações dos resultados obtidos & & 14 & 0 \\
\hline
\end{tabular}

Fonte: Dados da pesquisa conforme modelo de Bhatia (1993)

A descrição dos resumos de trabalho completo segundo o modelo de resumos de artigo científico proposto por Bhatia (1993) mostrou uma compatibilidade relativa entre os dados e o modelo. Dos quatro moves, apenas o primeiro e o segundo apresentaram um quantitativo de ocorrências significativo. Especificamente, a estratégia retórica mais recorrente foi a ER1, "Apontando os objetivos", do Move 1, com 11 ocorrências. Houve ainda ocorrências significativas do Move 2-ER1, "Apresentando o quadro teórico-metodológico adotado" e do Move 3-ER1, "Apontando observações sobre os dados analisados", 09 e 06 vezes respectivamente. Até aqui, o RTC não se afasta consideravelmente do RC em suas estratégias retóricas. Comparado a este, era de se esperar que o resumo de trabalho completo apresentasse ocorrências mais robustas das estratégias retóricas dos move 3 e 4, uma vez que o RC é produzido, muitas vezes, em um momento em que resultados e conclusões são ou inexistentes ou provisórios.

Assim, com relação ao modelo que fundamentou essa parte da análise, os resultados sugerem que o RTC não pode ser equiparado sem mais ao resumo de artigo científico, apesar de ambos se referirem a um texto-fonte completo e semelhante do ponto de vista da materialidade linguística. Considerando a concepção de colônia de gêneros, nossos resultados sugerem que, a julgar pelas diferenças entre seus resumos, também o trabalho completo em anais e o artigo publicado em periódicos podem ser gêneros significativamente diferentes do ponto de vista de seus propósitos comunicativos e da situação comunicativa a que atendem. 
Percebemos, assim, não apenas uma variação terminológica entre o resumo de artigo de pesquisa e o resumo de trabalho completo, mas também uma variação em termos de estratégias retóricas nas duas modalidades de resumo. Visando suprir as lacunas deixadas pela análise inicial do corpus de RTC, realizamos uma nova descrição retórica do gênero, agora mesclando elementos do modelo de Oliveira (2017) com o modelo de Bhatia (1993). Dessa análise, emergiu um quadro descritivo mais produtivo para a representação da distribuição das informações no gênero RTC, expresso, com as correspondentes ocorrências, na Tabela 3. Para maior clareza, as estratégias retóricas tomadas do modelo de Oliveira (2017) estão sinalizadas por uma linha pontilhada, ao lado das demais, provenientes de Bhatia (1993). Foram incluídas todas as ER realizadas e excluídas aquelas que não se confirmaram no corpus.

Tabela 3. Organização retórica de resumos de trabalho completo

\begin{tabular}{|c|c|c|}
\hline ORGANIZAÇÃO RETÓRICA & RTC & Oco \\
\hline \multicolumn{3}{|l|}{ MOVE 1: INTRODUZIR O PROPÓSITO } \\
\hline ER1: Apresentando informações contextuais da pesquisa ........ e/ou & 14 & 6 \\
\hline ER2: Apresentando o objeto de estudo .................................. e/ou & 14 & 7 \\
\hline ER3: Indicando a intenção do autor $\quad$ e/ou & 14 & 1 \\
\hline ER4: Apontando os objetivos & 14 & 11 \\
\hline \multicolumn{3}{|l|}{ MOVE 2: DESCREVER A METODOLOGIA } \\
\hline ER1: Apresentando o quadro teórico-metodológico & 14 & 9 \\
\hline ER2: Descrevendo os fundamentos teóricos ........................... e/ou & 14 & 4 \\
\hline ER3: Incluindo informações sobre o corpus $\quad$ e/ou & 14 & 3 \\
\hline ER4: Descrevendo os procedimentos ou métodos & 14 & 1 \\
\hline ER5: Indicando o escopo da pesquisa & 14 & 2 \\
\hline \multicolumn{3}{|l|}{ MOVE 3: SINTETIZAR OS RESULTADOS } \\
\hline ER1: Apontando observações sobre os dados analisados & 14 & 6 \\
\hline ER2: Apresentando os resultados & 14 & 1 \\
\hline \multicolumn{3}{|l|}{ MOVE 4: APRESENTAR AS CONCLUSÔES } \\
\hline ER1: Interpretando os resultados & 14 & 2 \\
\hline ER2: Apontando inferências sobre os resultados & 14 & 2 \\
\hline
\end{tabular}

Fonte: Elaboração própria

Diante do procedimento analítico textual, a partir dos modelos existentes para a descrição dos gêneros de resumo, encontramos subsídios para a interpretação de que os gêneros RC e RTC são caracterizados especificamente pelo contexto de produção e pelo reconhecimento dos produtores da necessidade de marcar a informação contextual e teórica das suas pesquisas. Esses aspectos são determinantes para os propósitos comunicativos realizados por ambos os gêneros.

Os dois procedimentos analíticos, contextual e textual, ofereceram, a nosso ver, um panorama significativo do que representa produzir gêneros de resumo dentro de e para um contexto específico. Em outras palavras, as análises contextual e textual se mostraram produtivas para a investigação sobre a variação entre os gêneros RC e RTC como relações entre gêneros e contexto no jogo da linguagem "como entidades complexas, dinâmicas, que se manifestam no mundo real e como parte da complexidade desse mundo" (BEZERRA, 2017, p. 48).

\section{CONSIDERAÇÕES FINAIS}

A análise empreendida neste estudo localizou e discutiu os gêneros resumo de comunicação e resumo de trabalho completo em duas direções complementares, correlacionando, a partir desses gêneros tão próximos e ao mesmo tempo distintos, dois conceitos fundamentais para os estudos da linguagem, o contexto e o texto.

A análise contextual contribui para salientar um aspecto que vai se tornando uma característica das abordagens mais recentes, de natureza sociorretórica, ao fenômeno comunicativo dos gêneros: nenhum gênero se explica à 
parte de complexas práticas sociais, discursivas e de letramento e, consequentemente, nenhum gênero pode ser adequadamente compreendido se não for na relação com outros gêneros.

Esse olhar para os gêneros possibilita a superação da nomeação e identificação simplista baseada predominantemente em aspectos formais. Neste trabalho, vimos como as duas modalidades de resumo adquirem sentido a partir do contexto específico de sua inserção entre as práticas de letramento de um evento acadêmico, mas essa relação contextual se estende para dimensões mais amplas que em última instância alcançam a comunidade acadêmica em geral, passando pela área disciplinar em específico.

Outro aspecto de expressivo potencial explicativo é a inserção desses gêneros em construtos teóricos como a cadeia e a colônia de gêneros, conceitos que tornam visíveis dois conjuntos de aspectos em que os gêneros se relacionam de forma a mediar as atividades desenvolvidas nos eventos acadêmicos, vistas como parte de um complexo sistema de atividades que norteia a carreira acadêmica. Na cadeia e na colônia de gêneros, o resumo de comunicação e o resumo de trabalho completo cumprem propósitos comunicativos muito específicos e são utilizados para realizar ações sociais que não se confundem.

A análise contextual é, em seguida, complementada por um atento olhar para os textos dos 29 resumos examinados neste estudo. No caso específico do evento de onde provieram os textos, as diferentes instruções da comissão organizadora para as duas modalidades de resumo impediam que elas pudessem se confundir, embora fossem produzidas pelo mesmo autor. No entanto, não é possível, igualmente, inferir que a produção de uma modalidade não interfira na escrita da outra. O aspecto em que essa relação, ora de aproximação, ora de distanciamento, parece se anular é no que diz respeito à fraca presença de informações sobre conclusões e até sobre resultados em ambas as modalidades.

Ocorre que as comunicações orais e as apresentações de pôsteres em eventos acadêmicos são espaços frequentemente ocupados por pesquisadores iniciantes ou em formação, cujas pesquisas se encontram ainda em andamento. Mesmo quando se trata de pesquisadores experientes, o resumo de comunicação, particularmente, pode se referir a um estudo "prometido"4 para o evento, de modo que efetivamente ainda não existem conclusões, o que explica a ênfase dos resumos na contextualização da pesquisa, nos objetivos, na metodologia e eventualmente na explicitação do quadro teórico.

A realização deste estudo também propiciou a testagem do modelo de resumo de artigo científico frente aos textos do resumo de trabalho completo, o que revelou a insuficiência desse modelo, levando-nos a mesclar as estratégias retóricas de dois modelos analíticos para uma descrição mais abrangente da organização retórica do resumo de trabalho completo. A correspondência apenas parcial entre a organização retórica do resumo de artigo científico e o resumo de trabalho completo, outrossim, parece sinalizar que uma análise contrastiva dos respectivos gêneros, artigo científico e trabalho completo, poderia ocasionar achados interessantes para o conhecimento da escrita acadêmica.

Em conclusão, acreditamos que um olhar multidimensional para os gêneros acadêmicos, tal como realizado neste trabalho, abrangendo contexto e texto, e valendo-se de construtos que deem conta das inter-relações que caracterizam os gêneros, pode trazer contínuas e ricas contribuições para o campo dos estudos da escrita acadêmica.

\section{REFERÊNCIAS}

BAZERMAN, C. (2011). Gêneros textuais, tipificação e interação. 4. ed. São Paulo: Cortez.

BAZERMAN, C. (2015). Retórica da ação letrada. São Paulo: Parábola Editorial.

BEZERRA, B. G. (2006). Gêneros introdutórios em livros acadêmicos. 2006. Tese (Doutorado em Letras/Linguística) - Universidade Federal de Pernambuco, Recife.

BEZERRA, B. G. (2007). Colônia de gêneros: o conceito e seu potencial analítico. In: SIMPÓSIO INTERNACIONAL DE ESTUDOS DE GÊNEROS TEXTUAIS, 4., 2007, Tubarão/SC. Anais [...]. Tubarão/SC, Universidade do Sul de Santa Catarina. p. 715-728

4. Swales e Feak (2009) tratam de abstracts e suas "promessas" para eventos científicos. 
BEZERRA, B. G. (2012). Letramentos acadêmicos na perspectiva dos gêneros textuais. Fórum Linguístico, Florianópolis, v. 9, n. 4, p. $247-258$, out./dez.

BEZERRA, B. G. (2017). Gêneros no contexto brasileiro: questões (meta)teóricas e conceituais. São Paulo: Parábola Editorial.

BEZERRA, B. G.; LÊDO, A. C. O. (2018). Gêneros acadêmicos e processos de letramento no ensino superior. In: PEREIRA, R. C. M. (org.). Escrita na universidade: panorama e desafios na América Latina. João Pessoa: Ideia. p. 173-205.

BHATIA, V. K. (1993). Analyzing genre: language use in professional settings. New York: Longman.

BHATIA, V. K. (1997). Análise de gêneros hoje. Trad. Benedito Gomes Bezerra. In: BEZERRA, B. G.; BIASI-RODRIGUES, B.; CAVALCANTE, M. M. (Orgs). Gêneros e sequências textuais. Recife: EDUPE, 2009. p. 159-195.

BHATIA, V. K. (2004). Worlds of written discourse: a genre-based view. London: Continuum.

BIASI-RODRIGUES, B. (1998). Estratégias de condução de informações em resumos de dissertações. Tese (Doutorado em Linguística) Universidade Federal de Santa Catarina, Florianópolis.

BORBA, V. M. R. (2004). Gêneros textuais e produção universitária: o resumo acadêmico. Tese (Doutorado em Letras) - Universidade Federal de Pernambuco, Recife.

CAMERON, L.; LARSEN-FREEMAN, D. (2008). Complex systems and applied linguistics. Oxford: Oxford University Press.

CARVALHO, F. F. (2010). Padrões de organização textual e lexicogramatical do gênero acadêmico resumo de tese: um estudo de caso. Trabalbos em Linguística Aplicada, v. 49, n. 1, p. 115-128.

DEVITT, A. J. (2004). Writing genres. Carbondale: Southern Illinois University Press.

FREADMAN, A. (2002). Uptake. In: COE, R.; LINGARD, L.; TESLENKO, T. (Eds.). The rbetoric and ideology of genre. Cresskill, NJ: Hampton Press. p. 39-53.

LARSEN-FREEMAN, D. (1997). Chaos/complexity science and second language acquisition. Applied Linguistics, v. 18, n. 2, p. $141-165$.

LEA, M. R.; STREET, B. V. (2006). The "academic literacies" model: theory and applications. Theory into Practice, v. 45, n. 4, p. $368-377$.

MCGRATH, L.; KAUFHOLD, K. (2016). English for Specific Purposes and Academic Literacies: eclecticism in academic writing pedagogy. Teaching in Higher Education, v. 21, n. 8, p. 933-947.

MEDEIROS, R. (2015). Resumo de dissertações e teses: a estrutura composicional à luz da Análise Textual dos Discursos. 2015. Tese (Doutorado em Estudos da Linguagem) - Universidade Federal do Rio Grande do Norte, Natal.

MIRANDA, F. (2014). Contribuição do modelo didático do gênero resumo de comunicação. In: PEREIRA, R. C. M. (org.). Ateliê de gêneros acadêmicos: didatização e construção de saberes. João Pessoa: Ideia. p. 273-314.

MOTTA-ROTH, D. (2011). Questões de metodologia em análise de gêneros. In: KARWOSKI, A. C.; GAYDECKA, B.; BRITO, K. S. (org.). Gêneros textuais: reflexões e ensino. 3. ed. São Paulo: Parábola Editorial. p. 153-173.

NOBRE, K. C.; BIASI-RODRIGUES, B. (2012). Sobre cadeias de gêneros. Linguagem em (Dis)curso, v. 12, n. 1, p. 213-230.

OLIVEIRA, J. H. P. (2017). Análise de gênero em contextos específicos: organização retórica e construção de sentidos no resumo de comunicação para eventos acadêmicos. 2017. Dissertação (Mestrado em Ciências da Linguagem) - Universidade Católica de Pernambuco, Recife.

OLIVEIRA, J. H. P. (2020). Análise de gêneros: organização retórica e terminológica do resumo de trabalho completo. Letras em Revista, Teresina, v. 11, n. 1, p. 110-121, jun. 
PAIVA, V. L. M. O. (2019). Gêneros da linguagem na perspectiva da complexidade. Linguagem em (Dis)curso, v. 19, n. 1, p. 67-85.

PIMENTEL, R. L. (2014). Um estudo sobre bibridização e agrupamento de gêneros no Facebook. Dissertação (Mestrado em Letras) Universidade Federal de Pernambuco, Recife.

RÄISÄNEN, C. (1999). The conference forum paper as a system of genres: a sociocultural study of academic conference practices in automotive crash-safety engineering. Gotemberg, Sweden: Acta Universitatis Gothoburgensis.

STREET, B. V. (2010). ‘Academic literacies approaches to genre’? Revista Brasileira de Linguística Aplicada, v. 10, n. 2, p. 347-361.

STREET, B. V. (2014). Práticas letradas e mitos do letramento. In: STREET, B. V. Letramentos sociais: abordagens críticas do letramento no desenvolvimento, na etnografia e na educação. São Paulo: Parábola Editorial.

SWALES, J. M. (1990). Genre analysis: English in academic and research settings. Cambridge: Cambridge University Press.

SWALES, J. M. (1998). Textography: toward a contextualization of written academic discourse. Research on Language and Social Interaction, v. 31, n. 1, p. 109-121.

SWALES, J. M. (2004). Research genres: exploration and applications. Cambridge: Cambridge University Press.

SWALES, J. M.; FEAK, C. B. (2009). Abstracts and the writing of abstracts. Michigan: The University of Michigan Press.

TARDY, C. M. (2016). Beyond convention: genre innovation in academic writing. Ann Arbor: University of Michigan Press.

VAN DIJK, T. A. (2012). Discurso e contexto. Trad. Rodolfo Ilari. São Paulo: Contexto.

VIANNA, C. A. D.; SITO, L.; VALSECHI, M.; PEREIRA, S. L. M. (2016). Do letramento aos letramentos: desafios na aproximação entre letramento acadêmico e letramento do professor. In: KLEIMAN, A. B.; ASSIS, J. A. (Orgs.). Significados e ressignificações do letramento: desdobramentos de uma perspectiva sociocultural sobre a escrita. Campinas, SP: Mercado de Letras. p. 27-59.

ZAKIR, M. A.; FUNO, L. B. A. (2011). Unidades retóricas em resumos de dissertações de mestrado do Projeto Teletandem Brasil: uma análise na perspectiva de gêneros textuais de Swales e Bhatia. In: SIMPÓSIO INTERNACIONAL DE LETRAS E LINGUÍSTICA, 2011, Uberlândia/MG. Anais [...]. Uberlândia/MG, Universidade Federal de Uberlândia. p. $1-14$.

Recebido: 10/7/2020

Aceito: 6/9/2021

Publicado: 14/9/2021 